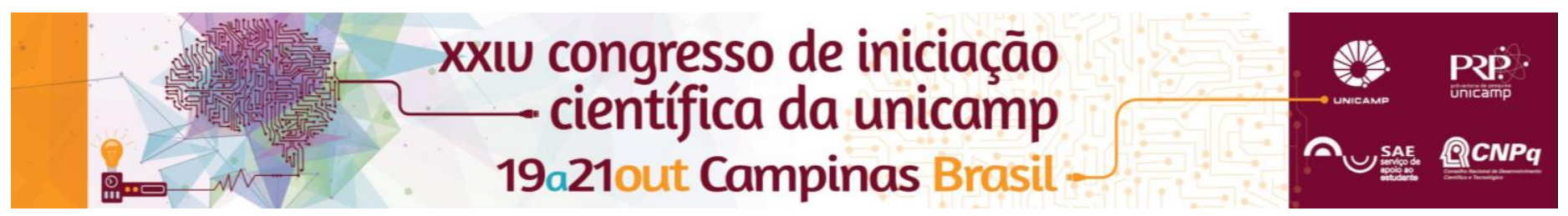

\title{
Fatores determinantes nas transições na carreira esportiva de atletas de squash.
}

\author{
Mairin Del Corto Motta*, Larissa Rafaela Galatti. Laboratório de Estudos em Pedagogia do Esporte, \\ Universidade Estadual de Campinas, Limeira, SP, Brasil. E-mail: mottamairin@gmail.com
}

\section{Resumo}

Este trabalho investigou se existem fatores em comum no desenvolvimento de carreiras esportivas de atletas de squash em diferentes fases. Foram encontradas semelhanças em 2 categorias (qualidade dos relacionamentos e cenários apropriados) e diferenças em 1 categoria (engajamento pessoal). O estudo mostrou a necessidade de pesquisas sobre a modalidade e também sobre a carreira esportiva de atletas.

Palavras-chave: Squash, Transição, Carreira Esportiva.

\section{Introdução}

O squash é uma modalidade esportiva de raquetes que foi criada em meados do século XIX. Por ser uma modalidade nova, o Brasil tem pouca expressão em termos de resultados internacionais acerca da modalidade. É relevante conhecer a trajetória esportiva desses atletas para que seja possível melhorar e gerar condições e processos de formação de atletas de alto rendimento, compreender como um atleta de squash consegue se manter e competir em alto nível, visto que a projeção social e financeira não é ampliada. O objetivo do trabalho é conhecer a trajetória de vida esportiva de atletas de squash em diferentes períodos da carreira esportiva e ainda identificar fatores que foram determinantes para os diferentes períodos de transição na carreira esportiva.

\section{Resultados e Discussão}

Foram entrevistados 3 atletas de squash: um atleta recentemente ex-juvenil; um atleta com a maior pontuação no ranking do Professional Squash Association (PSA); um atleta em final de carreira esportiva. O quadro teórico utilizado como base para análise e discussão foi o Quadro Teórico de Valores Pessoais para 0 Esporte $^{2}$ (figura 1). Através das entrevistas, foi utilizado a metodologia de Bardin ${ }^{1}$ utilizando as três fases: pré-análise, exploração do material e por fim tratamento dos resultados, inferência e interpretação.

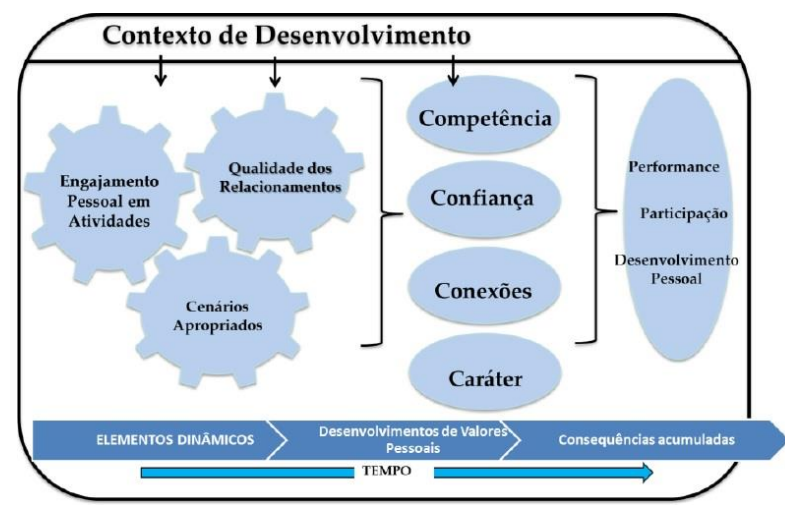

Figura 1. Quadro de Valores Pessoais para o Esporte².
As categorias utilizadas para análise foram os elementos dinâmicos: engajamento pessoal, qualidade dos relacionamentos, cenários apropriados. A partir das entrevistas transcritas, foi possível constatar algumas semelhanças entre os elementos de cada categoria, como também suas diferenças.

- Categoria engajamento pessoal: não foi encontrado elementos semelhante entre os atletas nas suas diferentes fases da carreira esportiva.

- Categoria qualidade dos relacionamentos: foi possível perceber semelhanças entre os atletas. Dois atletas já tiveram o mesmo treinador, as amizades foram importantes para a carreira esportiva e o apoio que a família desempenhou para a prática do esporte foram elementos em comum.

- Categoria cenários apropriados: foi possível perceber elementos em comum entre os atletas. O local da prática (academia) e apoio de algum patrocínio são os elementos que permeiam a carreira dos três atletas.

\section{Conclusões}

Elementos das categorias qualidade dos relacionamentos e cenários apropriados foram determinantes nas três carreiras esportivas, em diferentes fases, selando que são fatores importantes no desenvolvimento da carreira de um atleta de squash. Já a categoria engajamento pessoal não teve nenhum elemento em comum nas carreiras esportivas. São necessárias mais investigações acerca da modalidade e também sobre carreira esportiva.

\section{Agradecimentos}

Agradecemos ao CNPq, CAPES pelo apoio ao projeto.

\footnotetext{
${ }^{1}$ BENITES, L. C.; NASCIMENTO, J. V.; MILISTETD, M.; FARIAS, G. O Análise de conteúdo na investigação pedagógica em educação física: estudo sobre estágio curricular supervisionado. Revista Movimento, Porto Alegre, Rio Grande do Sul, v.22, n.1, p. 35-50, jan./mar. de 2016.
}

2 CÔTÉ, J.; TURNNIDGE, J.; EVANS, M.B. The dynamic process of development through sport/dinamicni proces razvoja prek sporta. Kinesiologia Slovenica, v.20, n.3, p.14, 2014 